\title{
Cell tracing reveals the transdifferentiation fate of mouse lung epithelial cells during pulmonary fibrosis in vivo
}

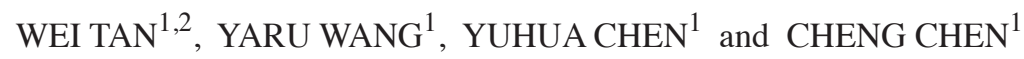 \\ ${ }^{1}$ Department of Developmental Cell Biology, Key Laboratory of Cell Biology of The Ministry \\ of Public Health, Key Laboratory of Medical Cell Biology of The Ministry of Education, \\ China Medical University, Shenyang, Liaoning 110122; ${ }^{2}$ Department of Respiratory and Critical Care Medicine, \\ The First Affiliated Hospital of China Medical University, Shenyang, Liaoning 110001, P.R. China
}

Received Feburary 11, 2021; Accepted June 22, 2021

DOI: $10.3892 / \mathrm{etm} .2021 .10622$

\begin{abstract}
Idiopathic pulmonary fibrosis (IPF) is a progressive and devastating interstitial lung disease. The origin of myofibroblasts is still to be elucidated and the existence of epithelial-mesenchymal transition (EMT) in IPF remains controversial. Hence, it is important to clarify the origin of fibroblasts by improving modeling and labeling methods and analyzing the differentiation pathway of alveolar epithelial cells (AEC) in pulmonary fibrosis with cell tracking technology. In the present study, adult transgenic mice with $S P C-r t T^{+/-} / t_{e t O}-C M V-C r e^{+/-} / m T m G^{+/-}$were induced with doxycycline for 15 days. The gene knockout phenomenon occurred in type II AECs in the lung and the reporter gene cell membrane-localized enhanced green fluorescence protein (mEGFP) was expressed in the cell membrane. The expression of Cre recombinase and SPC was analyzed using immunohistochemical (IHC) staining to detect the labeling efficiency. A repetitive intraperitoneal bleomycin-induced pulmonary fibrosis model was established, and the mice were sacrificed on day 28. The co-localization of mEGFP and mesenchymal markers $\alpha$-smooth muscle actin ( $\alpha$-SMA) and S100 calcium binding protein A4 (S100A4) were detected by multiple IHC staining. The results revealed that $\mathrm{Cre}$ was expressed in the airway and AECs in the lung tissue of adult transgenic mice with $S P C-r t T^{+/-} /$tet $_{7}-C M V-C r e^{+/-} / m T_{m} G^{+/-}$induced
\end{abstract}

Correspondence to: Dr Cheng Chen, Department of Developmental Cell Biology, Key Laboratory of Cell Biology of The Ministry of Public Health, Key Laboratory of Medical Cell Biology of The Ministry of Education, China Medical University, 77 Puhe Road, Shenbei New District, Shenyang, Liaoning 110122, P.R. China E-mail: chchen@cmu.edu.cn

Abbreviations: IPF, idiopathic pulmonary fibrosis; EMT, epithelial-mesenchymal transition; $\alpha$-SMA, $\alpha$-smooth muscle actin; S100A4, S100 calcium-binding A4; AEC, alveolar epithelial cell; IHC, immunohistochemistry; SPC, surfactant protein C

Key words: bleomycin, epithelial-mesenchymal transition, idiopathic pulmonary fibrosis, cell tracing, multiple IHC staining by doxycycline; the labeling efficiency in the peripheral lung tissue was $63.27 \pm 7.51 \%$. mEGFP was expressed on the membrane of type II AECs and their differentiated form of type I AECs. Expression of mEGFP was mainly observed in the fibrotic region in bleomycin-induced pulmonary fibrosis; $1.94 \pm 0.08 \%$ of $\alpha$-SMA-positive cells were mEGFP-positive and $9.68 \pm 2.06 \%$ of S100A4-positive cells were mEGFP-positive in bleomycin-induced pulmonary fibrosis. In conclusion, the present results suggested that while EMT contributes to the pathogenesis of pulmonary fibrosis, it is not the major causative factor of this condition.

\section{Introduction}

Idiopathic pulmonary fibrosis (IPF) is a persistent and destructive interstitial lung disease of unknown etiology with an estimated median survival time of 3-5 years following diagnosis (1-3). It is characterized by abnormal proliferation and remodeling of fibroblasts and myofibroblasts. The aggregation of myofibroblasts leads to the deposition of extracellular matrix, an abnormal wound healing process and remodeling of the lung structure (4). IPF may be an epithelial-driven disease and the damage and repair of alveolar epithelial cells (AECs) are important incentives for pulmonary fibrosis (5). Epithelial cells may lose their normal polarity and shape under various stimuli, which leads to epithelial-mesenchymal transition (EMT) (6).

Whether EMT occurs during pulmonary fibrosis remains controversial $(7,8)$. Cell tracking technology is useful for analyzing the differentiation path of AECs in pulmonary fibrosis and the origin of fibroblasts. Several studies with lineage tracing supported the existence of EMT during pulmonary fibrosis. Kim et al (9) used a SPC-rtTA, tet $\mathrm{O}_{7}-\mathrm{CMV}-\mathrm{Cre}$ induction expression system to induce the expression of a lacZ reporter gene in the AECs of transgenic mice. Triple transgenic mice were then treated with intranasal instillation of a replication-deficient adenovirus (Ad) expressing constitutively active TGF $\beta-1$, to establish a pulmonary fibrosis model; 33\% of vimentin-positive cells were $X$-gal positive (9). Other studies applied $\beta$-galactosidase as the detection marker of AECs and the intratracheal instillation of bleomycin to establish the pulmonary fibrosis 
model, revealing the co-localization of $\beta$-galactosidase and mesenchymal markers (10-14). Rock et al (15) used the tamoxifen-induced SPC-CreER ${ }^{\mathrm{T} 2}$ (new mutations on the estrogen receptor that enhances tamoxifen binding ability) system, labeled ATII cells and performed intratracheal instillation of bleomycin to establish the pulmonary fibrosis model, which failed to prove the existence of EMT. Chilosi et al (16) and another study (17) indicated that the markers zinc finger E-box binding homeobox 1 and $\beta$-catenin of the EMT signaling pathway were co-localized with epithelial markers in the fibrotic region of human pulmonary fibrosis. As aforementioned, the results of lineage tracing studies are contradictory and inconsistent with the results of clinicopathological studies (9-17). Thus, future studies should comprehensively investigate the mechanisms of bleomycin-induced pulmonary fibrosis, select a type of modeling similar to the clinical-pathological process, and use neutral and efficient labeling and gene reporting systems in lineage tracing studies to determine whether EMT occurs in pulmonary fibrosis, which is crucial for the development of therapeutic strategies for IPF.

In the present study, the classic model of pulmonary fibrosis was induced by intraperitoneal injection of bleomycin. Adult $\mathrm{SPC}-\mathrm{rtTA}^{+/-} / \mathrm{tetO}_{7}-\mathrm{CMV}-\mathrm{Cr}^{+/-} / \mathrm{mTmG}^{+/-}$mice were induced by doxycycline and the labeled AECs were detected by cell membrane-localized enhanced green fluorescence protein (mEGFP). The co-localization of mEGFP and mesenchymal markers was detected by multiple immunohistochemical staining to analyze whether EMT occurred in AECs during pulmonary fibrosis.

\section{Materials and methods}

Establishment of transgenic animal system. SPC-rtTA mice [B6.Cg-Tg(SFTPC-rtTA)5Jaw/J] and tetO ${ }_{7}$-CMV-Cre mice $\left[\mathrm{B} 6 . \mathrm{Cg}-\mathrm{Tg}\left(\right.\right.$ tetO $_{7}$-cre $\left.) 1 \mathrm{Jaw} / \mathrm{J}\right]$ were purchased from the Jackson Laboratory. mTmG mice [B6.129(Cg)$G t(\operatorname{ROSA}) 26$ Sor $\left.^{\text {tm } 4(A C T B-t d T o m a t o,-E G F P) L u o} / J\right]$ were obtained from Nanjing BioMedical Research Institute of Nanjing University. All mice were of the C57BL6 strain. First, SPC-rtTA and tetO $\mathrm{O}_{7} \mathrm{CMV}-\mathrm{Cre}$ mice were mated to obtain those with both $S P C-r t T A$ and $t_{e t} O_{7}-C M V-C r e$ genes, which were then mated with $\mathrm{mTmG}$ mice to obtain transgenic mice with the genotype $S P C-r t T_{A}^{+/-} /$tet $_{7}-C M V-C r e^{+/-} / m T_{m} G^{+/-}$. Male transgenic mice (aged 8-12 weeks) were induced by adding $0.5 \mathrm{mg} / \mathrm{ml}$ doxycycline to their drinking water for 15 days and the expression of Cre in the lungs was examined by multiple IHC in a number of mice. The remaining mice were raised with normal water and food for $>20$ days, after which multiple IHC was performed to detect the expression of mEGFP and SPC in the lung tissue. Animals that reached the endpoint of the experiment were then sacrificed by cervical dislocation to observe the lungs by multiple IHC staining. The animal care and use complied with the Provisions and General Recommendation of the Chinese Experimental Animals Administration Legislation (no. GB14925-2010). The animals were housed at a temperature of $23 \pm 2{ }^{\circ} \mathrm{C}$, relative humidity of $55 \pm 15 \%$, and a 12-h light/dark cycle. Access to standard food and sterile drinking water was ensured. Animal health and behavior were monitored every day. The study protocol was approved by the
Institutional Animal Care and Use Committee (IACUC) of China Medical University (CMU) (IACUC issue no. 14031M).

Bleomycin-induced pulmonary fibrosis in mice. Adult male transgenic mice aged 8-12 weeks with the genotype $\mathrm{SPC}-\mathrm{rtTA} \mathrm{A}^{+/} / \mathrm{tetO}_{7}-\mathrm{CMV}-\mathrm{Cr} \mathrm{e}^{+/-} / m \mathrm{Tm}^{+/-}$were induced with doxycycline for 15 days. Mice were then provided normal water and food for one week. Subsequently, mice were randomly divided into two groups: Experimental group $(n=3$; bleomycin-induced pulmonary fibrosis) and control group $(n=3)$. The body weight of the mice was $20-25 \mathrm{~g}$. The mice in the experimental group were intraperitoneally injected with bleomycin (Hanhui; $40 \mathrm{USP} / \mathrm{kg}$ in $0.2 \mathrm{ml}$ of $0.9 \%$ physiological saline solution) on days 0 and 2 , followed by $20 \mathrm{USP} / \mathrm{kg}$ on days 4 and 6 , and $10 \mathrm{USP} / \mathrm{kg}$ on days 9, 12, 15, 18, 21, 24 and 27 to avoid death. The mice in the control group were injected with $0.2 \mathrm{ml}$ of normal saline. No animals died during the experimental period. The mice in both groups were sacrificed by cervical dislocation on day 28 .

Histological examination. After the lungs were removed, the right lung tissue was immediately fixed in $4 \%$ paraformaldehyde and the tissues were dehydrated and embedded in paraffin. Subsequently, $5-\mu \mathrm{m}$ paraffin sections were prepared and the tissues were stained with H\&E (cat. no. WK297; Biolab) and examined under a microscope (Olympus Corporation). Masson's trichrome staining (cat. no. G1340; Beijing Solarbio Science \& Technology Co., Ltd.) was also performed to evaluate fibrosis (collagen fibers) following the manufacturer's standard protocols. The samples were inspected using a BX-51 microscope (Olympus Corporation). ImagePro Plus v. 6.0 (Media Cybernetics, Inc.) was used to calculate the integrated optical density and area value for each image, from which the average optical density value was then calculated.

IHC staining. The paraffin sections $(5 \mu \mathrm{m})$ of mouse lungs were deparaffinized and then subjected to antigen retrieval in citrate buffer (10 mM sodium citrate, $\mathrm{pH}$ 6.0) with heating to $100^{\circ} \mathrm{C}$ for $10 \mathrm{~min}$. Subsequently, the Immunohistochemical Staining kit (cat. no. SP-9001; OriGene Technologies, Inc.) was used to complete the follow-up experiments. The sections were blocked with normal goat plasma for $20 \mathrm{~min}$ at room temperature and then incubated overnight at $4^{\circ} \mathrm{C}$ with the following primary antibodies: Cre recombinase antigen (rabbit; dilution, 1:100; cat. no. 15036S; Cell Signaling Technology, Inc.), GFP antigen (rabbit; dilution, 1:200; cat. no. 2956S; Cell Signaling Technology, Inc.), SPC antigen (rabbit; dilution, 1:50; cat. no. sc-13979; Santa Cruz Biotechnology, Inc.), $\alpha$-smooth muscle actin ( $\alpha$-SMA) antigen (rabbit; dilution, 1:100; cat. no. ab5694; Abcam) and S100 calcium binding protein A4 (S100A4) antigen (rabbit; dilution, 1:100; cat. no. 13018S; Cell Signaling Technology, Inc.). The sections were incubated for 20 min with a streptavidin-biotin-peroxidase complex and incubated with secondary antibody for $20 \mathrm{~min}$ at $37^{\circ} \mathrm{C}$. The AEC Chromogenic Reagent (Boster Biological Technology) and hematoxylin were used for color development and counterstaining, respectively. The samples were examined using a BX-51 microscope (Olympus Corporation) at a magnification of $\mathrm{x} 100$ or $\mathrm{x} 200$. 

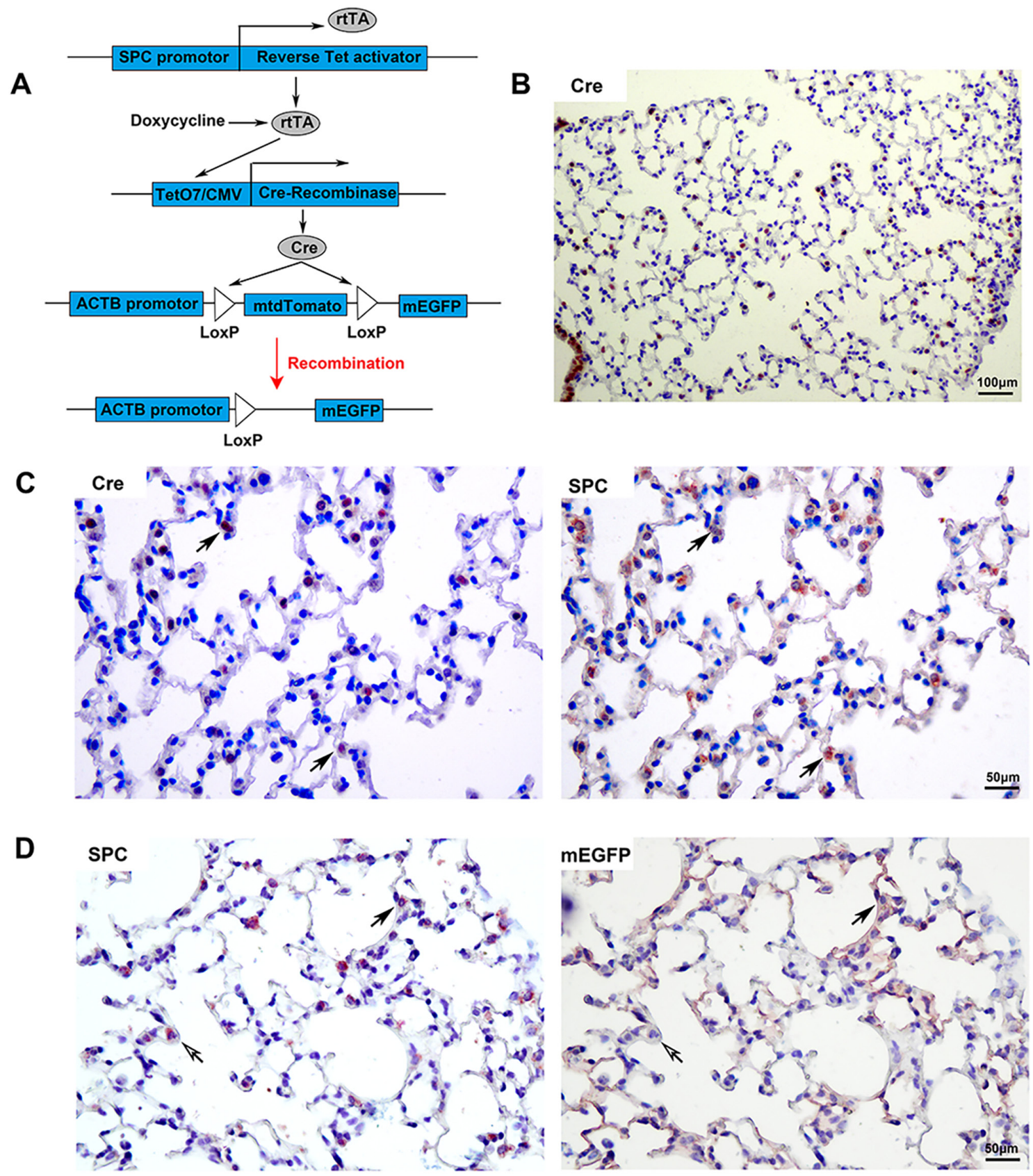

Figure 1. Establishment of transgenic mice. (A) Principle of tissue-specific inducible transgenic mice system. (B) Cre was detected in lung tissue by IHC staining (scale bar, $100 \mu \mathrm{m}$ ). (C) Cre was detected by IHC staining in the peripheral lung tissue and then SPC was detected by IHC staining after antibody stripping. The solid arrows indicate that Cre and SPC were co-localized in the same cell. (D) SPC was detected by IHC staining and then mEGFP was detected by IHC staining after antibody stripping. The solid arrows indicate that SPC and mEGFP were co-localized in the same cell, while the hollow arrows indicate that SPC and mEGFP were not co-localized in the same cell (scale bars, $50 \mu \mathrm{m}$ ). IHC, immunohistochemistry; mEGFP, cell membrane-localized enhanced green fluorescence protein; SPC, surfactant protein C; ACTB, $\beta$-actin.

Multiple IHC staining. Following micrograph acquisition after the first IHC staining, the samples were washed with an alcohol gradient $(25,50,70,85,95,85,70,50$ and $25 \%)$. The antibodies were then stripped with a buffer containing 65 mM Tris-HCl pH 6.8 (Sigma-Aldrich; Merck KGaA), $1 \%$ SDS (Beijing Solarbio Science \& Technology Co., Ltd.), 0.113M 2-mercaptoethanol (Sigma-Aldrich; Merck KGaA), $0.1 \mathrm{M} \mathrm{NaCl}$ and $2 \mathrm{M}$ urea (Sigma-Aldrich; Merck KGaA) in a $56^{\circ} \mathrm{C}$ water bath with agitation twice for $30 \mathrm{~min}$ each time. After antibody stripping, the sections were washed with distilled water for $30 \mathrm{~min}$ ( $5 \mathrm{~min}$ each time) at room temperature. The sections were then immunostained again, as described earlier.

Reverse-transcription-quantitative (RT-q)PCR. Total RNA was isolated from the left lobe of each mouse lung (RNAiso Plus; cat. no. D9108AT; Takara Bio, Inc.) and transcribed into cDNA according to the kit (cat. no. RR037A; Prime Script ${ }^{\circledR}$ RT reagent Kit Perfect Real-Time; Takara Bio, Inc.). Amplification and quantitation were performed on an ABI7500 Real-time PCR System with Takara SYBR ${ }^{\circledR}$ Premix Ex Taq ${ }^{\mathrm{TM}}$ II (cat. no. RR820A; Takara Bio, Inc.). The following primers were 
A
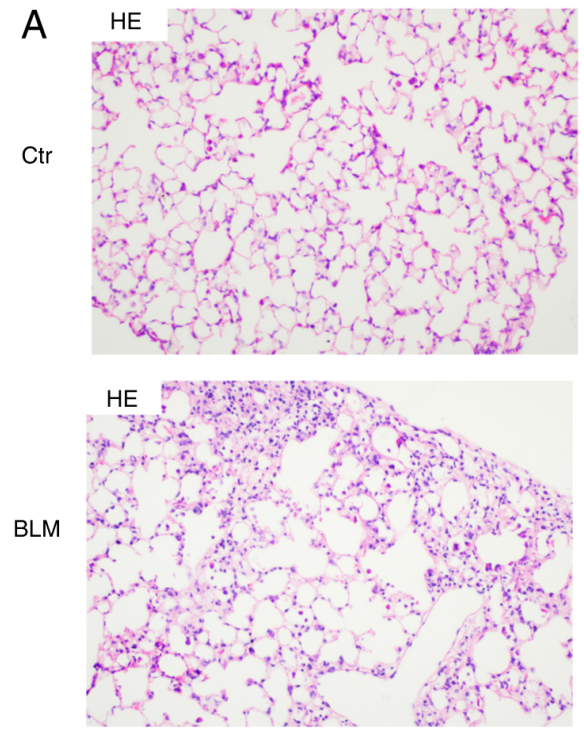

B

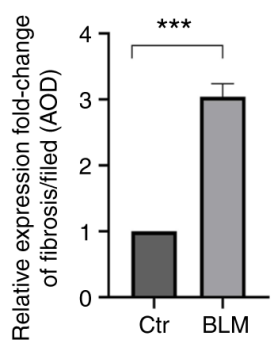

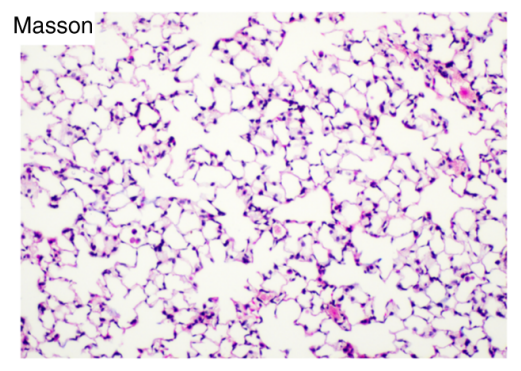
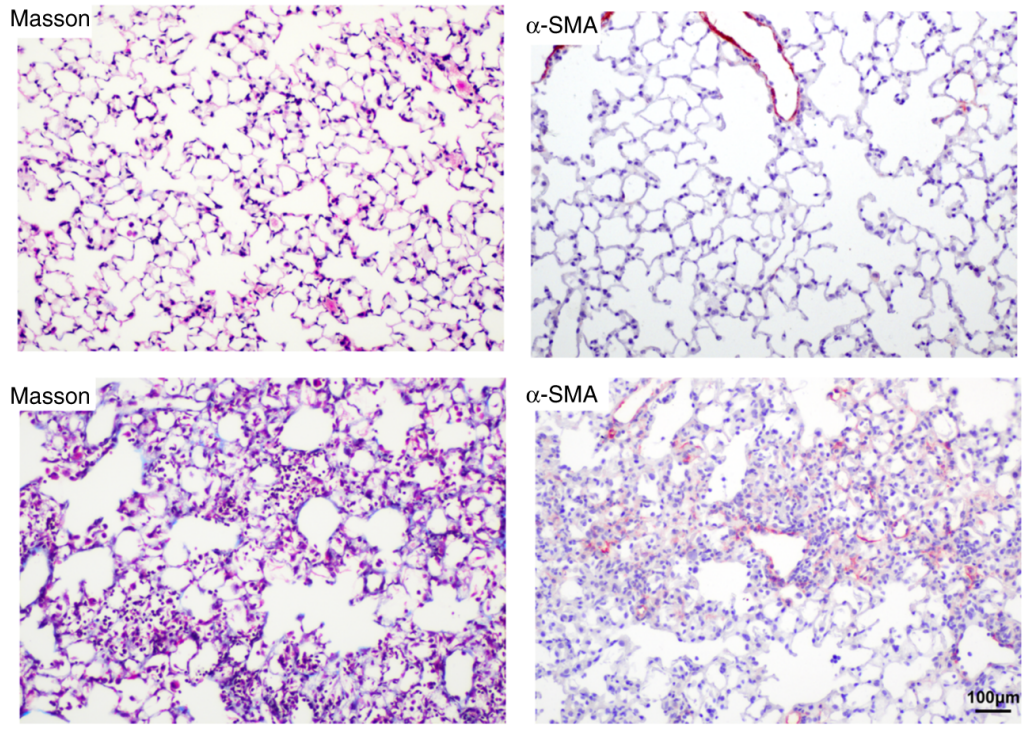

C

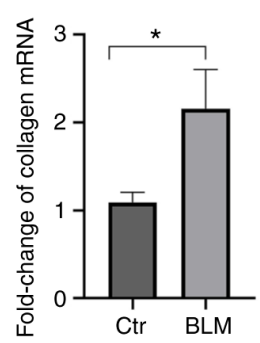

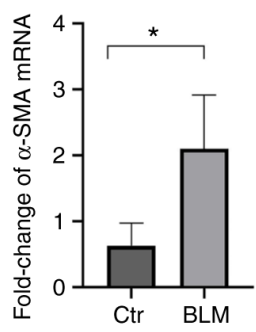

Figure 2. Bleomycin-induced pulmonary fibrosis in mice. (A) Lung tissue sections were prepared on day 28 and subjected to H\&E and Masson staining. $\alpha$-SMA was detected in the lungs by immunohistochemical staining (scale bars, $50 \mu \mathrm{m}$ ). (B) Masson staining and $\alpha$-SMA was quantified as the relative expression fold change of fibrosis/field and $\alpha$-SMA/field (AOD) in each group. (C) Expression of $\alpha$-SMA and collagen mRNA in the lungs of the control mice and experimental mice on day $28 .{ }^{*} \mathrm{P}<0.05,{ }^{* * * *} \mathrm{P}<0.001$. Ctr, control; BLM, bleomycin; SMA, smooth muscle actin; AOD, average optical density.

used: $\alpha$-SMA forward, 5'-CCAACTGGGACGACATGGAA-3' and reverse, 5'-GAGGCATAGAGGGACAGCAC-3'; collagen forward, 5'-ACATGTTCAGCTTTGTGGACC-3' and reverse, 5'-TAGGCCATTGTGTATGCAGC-3'; GAPDH forward, 5'-GGCATTGTGGAAGGGCTCAT-3' and reverse, 5'-GGC AGCACCAGTGGATGCAG-3'. Quantification was performed by the $2^{-\Delta \Delta C t}$ method (18) with GAPDH for normalization.

Statistical analysis. Values are expressed as the mean \pm standard deviation. Comparisons between groups were performed by using unpaired the independent t-test. All analyses were performed using GraphPad Prism 5 (GraphPad Software, Inc.). $\mathrm{P}<0.05$ was considered to indicate a statistically significant difference.

\section{Results}

Labeled type II AECs and their descendants may be detected by multiple IHC staining. The transgenic mouse system involves three transgenic components. It expressed rtTA under the control of recombinant SPC promoter; in the presence of inducer doxycycline, the transcription factor rtTA was able to activate the expression of Cre recombinase. The mtdTomato sequence flanked by Loxp sites was removed by site-specific recombinase Cre. Thus, mEGFP was constitutively and irreversibly expressed under the control of the
ACTB promotor (Fig. 1A). Adult transgenic mice with the genotype $\mathrm{SPC}$-rtTA $\mathrm{TA}^{+/ /} /$tet $_{7}-\mathrm{Cre}^{+/-} / m \mathrm{mTm}^{+/-}$were induced with doxycycline for 15 days. Cre was determined to be localized in the airway and peripheral lung tissues of doxycycline-induced knockout transgenic mice (Fig. 1B). Co-localization of Cre and SPC was observed in the peripheral lung tissue of transgenic mice (Fig. 1C); the proportion of $\mathrm{Cre}^{+} \mathrm{SPC}^{+} / \mathrm{SPC}^{+}$was $63.27 \pm 7.51 \%$.

Male transgenic mice were induced with doxycycline, and the multiple IHC staining technique was used to detect the expression of SPC and EGFP (Fig. 1D). mEGFP was detected in the peripheral lung tissue of transgenic mice. Certain $\mathrm{mEGFP}^{+}$cells were type II AECs (with expression of SPC, which is a type II AEC marker); other mEGFP cells spread over the surface were type I AECs (without expression of SPC). The expression of mEGFP was caused by gene recombination when their parent cells were type II AECs. There were also a small number of $\mathrm{SPC}^{+}$cells that did not express mEGFP in lung tissue, which suggests that gene knockout efficiency was $<100 \%$. The right panel of Fig. 1D indicates that the membrane bonded with EGFP that was detected, while there was no SPC stain in the cytoplasm, which indicated that the anti-SPC antibody used in the first round of IHC staining was fully stripped after IHC staining. Furthermore, it did not interfere with the second round of IHC staining to detect mEGFP. All of these results 
A
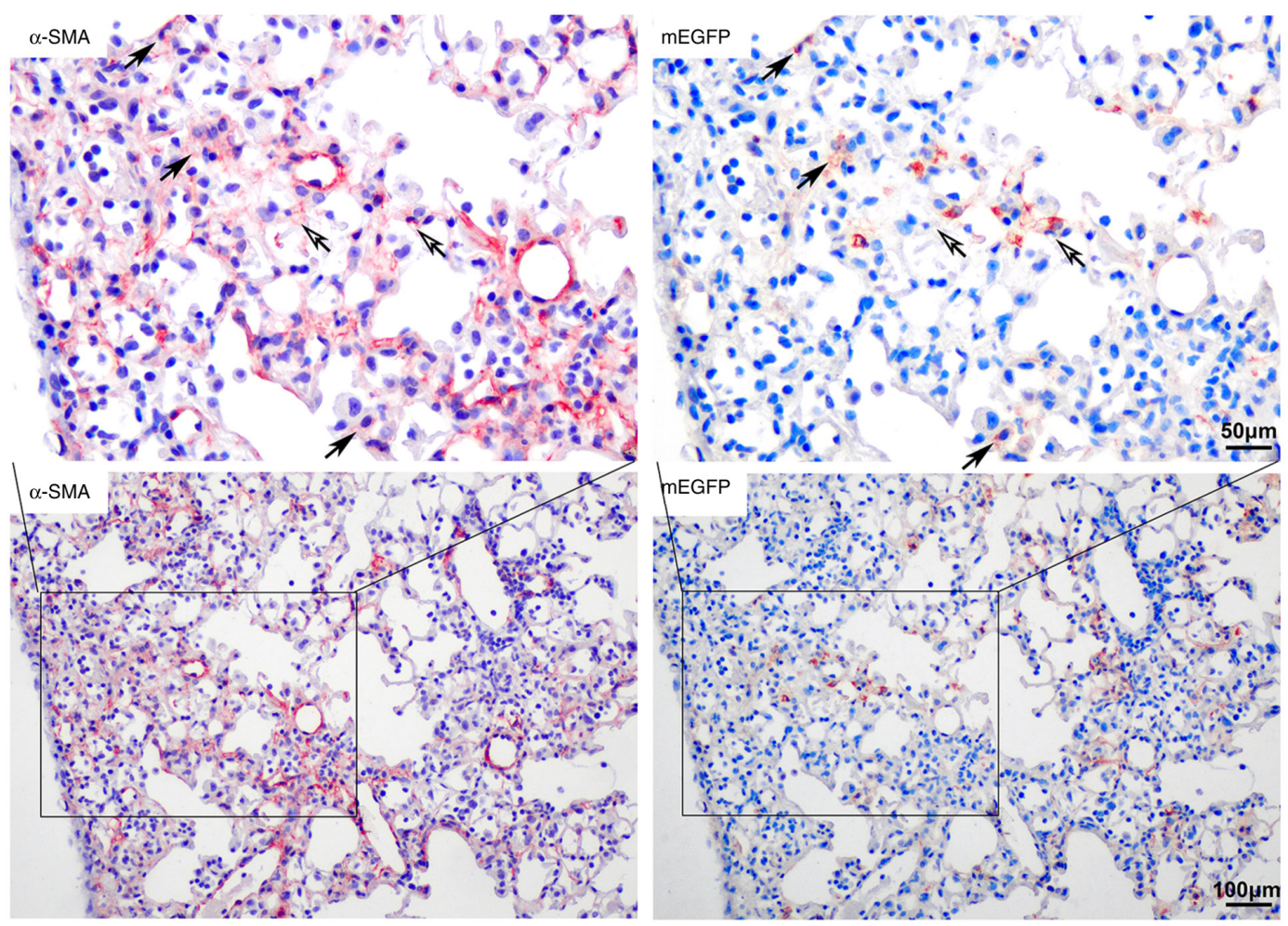

B
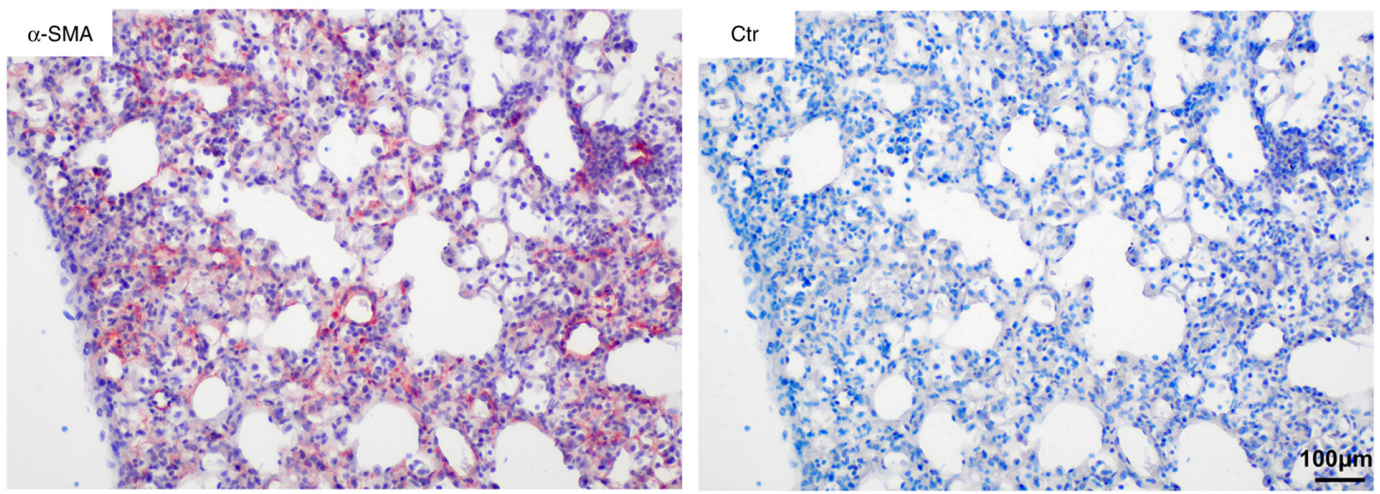

Figure 3. Co-localization of $\alpha$-SMA and mEGFP in the lung tissues of mice with bleomycin-induced pulmonary fibrosis. (A) $\alpha$-SMA was detected in the lungs of mice with bleomycin-induced pulmonary fibrosis by IHC staining. Subsequently, mEGFP was detected by IHC staining after antibody stripping. The solid arrow indicates that $\alpha$-SMA and mEGFP were co-localized in the same cell; the hollow arrow indicates that $\alpha$-SMA and mEGFP were not co-localized in the same cell (scale bars, $100 \mu \mathrm{m}$ in lower panel and $50 \mu \mathrm{m}$ in magnified windows). (B) $\alpha$-SMA was detected in the adjacent sections of A by IHC staining; subsequently, the sections were stripped and those with no addition of the first antibody were used as the control group for A (scale bar, $100 \mu \mathrm{m}$ ). SMA, smooth muscle actin; IHC, immunohistochemistry; mEGFP, membrane-bound enhanced green fluorescence protein.

demonstrated that multiple IHC staining may be used for cell lineage tracing.

Bleomycin-induced pulmonaryfibrosis in transgenic mice. After induction and modeling, the mice in the experimental group exhibited decreased appetite, weight loss (Fig. S1), unkempt and dull fur and shortness of breath. On day 28 , histopathological examination indicated inflammatory-cell infiltration in the alveolar septum and destruction of the normal alveolar structure in the experimental group. Masson staining indicated that the alveolar structure was destroyed, the normal structure disappeared, and obvious collagen fiber deposition occurred in the experimental group compared with the control group. Furthermore, the expression of $\alpha$-SMA and collagen mRNA in the lung tissue was significantly higher in the experimental group than in the control group $(\mathrm{P}<0.05)$, which indicated that myogenic fibroblasts and fibrotic foci were formed (Fig. 2).

Co-expression of $\alpha$-SMA and mEGFP in bleomycin-induced pulmonary fibrotic lesions. A small number of cells in fibrotic foci in mice with bleomycin-induced pulmonary fibrosis were type II AECs. Certain $\alpha$-SMA ${ }^{+}$cells expressed mEGFP simultaneously in the center of the lesion area and certain mEGFP ${ }^{+}$ cells on the alveolar wall also exhibited $\alpha$-SMA staining signals. Most mEGFP ${ }^{+}$cells had no $\alpha$-SMA expression. The number of $\alpha$-SMA/mEGFP double-positive cells in the fibrotic tissue was low, as $1.94 \pm 0.08 \%$ of $\alpha$-SMA-positive cells were mEGFP-positive. Most of the cells in the fibrotic foci did not express mEGFP and they were no descendants of type II AECs (Fig. 3). 

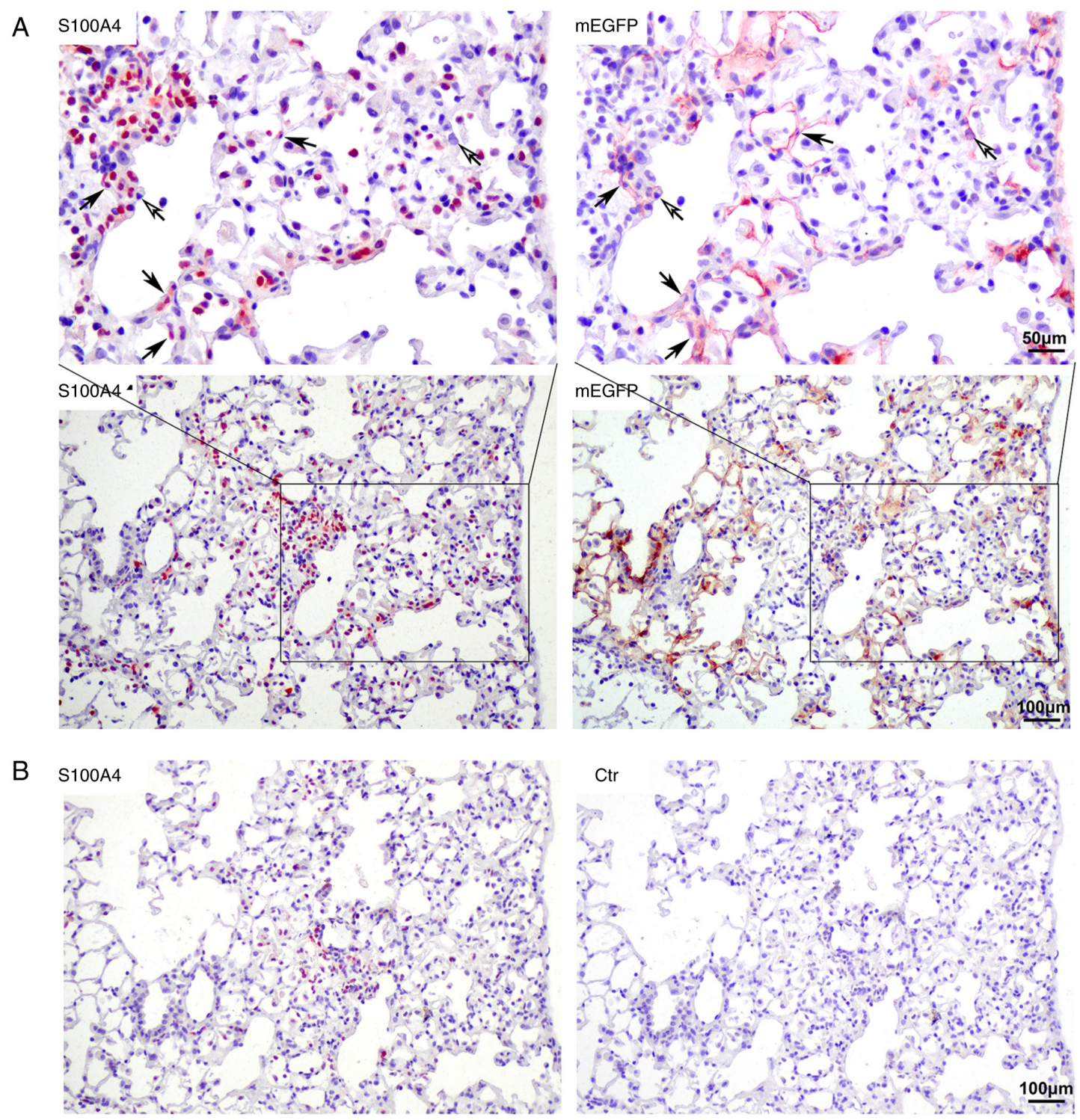

Figure 4. Co-localization of S100A4 and mEGFP in the lung tissues of mice with bleomycin-induced pulmonary fibrosis. (A) S100A4 was detected in the lungs of mice with bleomycin-induced pulmonary fibrosis by IHC staining; subsequently, mEGFP was detected by IHC staining after antibody stripping. The solid arrow indicates that S100A4 and mEGFP were co-localized in the same cell, while the hollow arrow indicates that S100A4 and mEGFP were not co-localized in the same cell (scale bars, $100 \mu \mathrm{m}$ in lower panel and $50 \mu \mathrm{m}$ in magnified windows). (B) S100A4 was detected in the adjacent sections of A by IHC staining. Subsequently, the sections were stripped and those with no addition of the first antibody were used as the control group for A (scale bar, $100 \mu \mathrm{m}$ ). IHC, immunohistochemical; mEGFP, membrane-bound enhanced green fluorescence protein; S100A4, S100 calcium binding protein A4.

Cells co-expressing S100A4 and mEGFP in bleomycininduced pulmonary fibrotic lesions. Numerous S100A4-positive cells were observed in the pulmonary fibrotic lesion areas in the lungs of the model mice. S100A4 is also considered to be an important marker of fibrosis (19). Multiple IHC staining indicated that only a small number of S100A4-positive cells originated from type II AECs and $9.68 \pm 2.06 \%$ of S100A4-positive cells were mEGFP-positive. These were S100A4 and mEGFP double-positive cells and they were mainly distributed on the alveolar wall. Thus, the origin of most of the $\mathrm{S} 100 \mathrm{~A} 4^{+}$cells was not related to type II AECs (Fig. 4).

\section{Discussion}

In the present study, the classic intraperitoneal administration of bleomycin was used to establish pulmonary fibrosis in mice (20). Lineage-tracing studies with neutral and efficient labeling and gene reporting systems were performed to clarify whether EMT existed in pulmonary fibrosis. The results indicated that EMT contributes to the pathogenesis of pulmonary fibrosis, but it is not the major causative factor of this condition.

Bleomycin may be injected using intratracheal administration or systemically (intraperitoneally, intravenously or subcutaneously) (21). The intratracheal injection has been widely applied in lineage tracing studies (10-14). When injected through the trachea into the lungs, bleomycin directly damages AECs. Fibrosis induced by this method has been reported to be self-limiting after 28 days. Previous studies also suggested that this routine may be inconsistent with the pathological changes in human IPF (20-24). When bleomycin is systemically injected, the initial site of injury is 
the pulmonary vascular endothelium; after endothelial cell injury, the drug targets alveolar epithelium. When bleomycin is intraperitoneally delivered, the dose may be easily defined and the method is simple to perform; it may cause repeated tissue damage and repair, followed by irreversible pulmonary fibrosis, which is considered more clinically relevant than intratracheal administration $(20,21,25)$. In the present study, intraperitoneal administration of bleomycin, which is closer to the clinicopathological changes of IPF, was used to establish pulmonary fibrosis in mice.

Existing lineage tracing experiments, cell labeling methods and reporter gene systems are somewhat limited. First, the inducers used in some research may have a potential effect on fibrosis (15). Tamoxifen, an inducer of the CreER ${ }^{\mathrm{T} 2}$ system, is a selective estrogen receptor modulator, which is also known for its inhibitory effect on the production of TGF- $\beta$. Its anti-fibrotic effect has been examined in certain fibrotic diseases (26). There is an interval between the end of induction and the beginning of the modeling that serves to avoid side effects of tamoxifen. However, this interval was different between studies on pulmonary fibrosis $(15,27)$. Furthermore, proper labeling time is important for accurately controlling the labeling range. Certain studies were initiated from the mouse embryonic stage, which may lead to a wider range of labeling (28). In addition, a suitable reporter gene should be used to mark target cells. Previous studies have indicated that $\beta$-galactosidase is expressed in both fibroblasts and epithelial cells of human lung tissue affected by IPF and bleomycin-induced pulmonary fibrosis $(29,30)$. X-gal staining should be avoided in pulmonary fibrosis cell tracing studies. In the present study, the $S P C-r t A^{+/-} /$tet $_{7}-C M V-C r e^{+/-} / m T_{m} G^{+/-}$system was used and induced with doxycycline from adulthood. The inducer doxycycline and the reporter gene product mEGFP in this system are neutral and do not interfere with pulmonary fibrosis; thus, more objective results may be observed.

In the present study, the labeling method of type II AECs was improved to obtain more objective tracking results. The $S P C-r t T A^{+/-} /$tet $_{7}-C M V-C r e^{+/-} / m T m G^{+/-}$system was used and induced with doxycycline from adulthood. The results indicated that only type II epithelial cells expressed Cre in the peripheral lung tissue. The labeling efficiency in AEC II of transgenic mice was $63.27 \pm 7.51 \%$ by IHC co-localization with Cre and SPC. At the beginning of bleomycin modeling, the labeled cells were type II epithelial cells, while there was only a small number of newly differentiated type I epithelial cells. By using mEGFP as a reporter gene, the outline of the cell was marked without this being disturbed by cell senescence. Multiplex IHC staining techniques are useful for examining changes in the expression of target molecules and the basic histological changes in the lesion while avoiding background fluorescence interference and sensitivity to low-abundance antigens $(31,32)$. The present study reproduced the process of differentiation of type II AECs in bleomycin-induced pulmonary fibrosis, which is more clinically relevant than intratracheal administration.

The expression of mEGFP was detected in the fibrotic region, suggesting the existence of progeny cells of epithelial cells. Multiplex IHC staining indicated that certain cells were $\alpha-\mathrm{SMA}^{+} / \mathrm{mEGFP}^{+}$or $\mathrm{S} 100 \mathrm{~A}^{+} / \mathrm{mEGFP}^{+}$double-positive in bleomycin-induced pulmonary fibrosis. This confirms that EMT may be one of the origins of myofibroblasts. However, only a small proportion of fibroblasts was identified as originating from type II epithelial cells. This suggests that the origin of cells in fibrotic lesions is complex. Fibroblasts may have other sources, including the proliferation of lung fibroblasts, transformation of vascular endothelial cells and pericytes, as well as differentiation of bone marrow progenitor cells $(33,34)$. On the other hand, EMT may not be the only direct phenotypic transformation of epithelial cells into fibroblasts. Yamaguchi et al (35) reported that fibroblastic foci were covered with alveolar epithelium and certain AECs also expressed vimentin, implying partial EMT, and those cells had the functions of both epithelial cells and mesenchymal cells, such as adhesion and migration. Whether epithelial cells with mesenchymal markers may release profibrotic factors or exhibit a partial EMT phenotype requires further investigation. It was noticed that the distribution of $\alpha-\mathrm{SMA}^{+} / \mathrm{mEGFP}^{+}$or $\mathrm{S} 100 \mathrm{~A} 4^{+} / \mathrm{mEGFP}^{+}$double-positive cells in fibrotic lesion was not exactly the same. In patients with IPF and bleomycin-induced pulmonary fibrosis, S100A4 may be secreted by fibroblasts and promote pulmonary fibrosis through fibroblast activation $(36,37)$. How S100A4 participates in abnormal epithelial-mesenchymal interactions requires further investigation.

Of note, the present study had several limitations. First, the sample size of mice used in the experiment was relatively small. In the present study, mice with a uniform genetic background and uniform modeling methods were strictly selected, which met the minimal requirement for sufficient statistical power. Furthermore, $\alpha-\mathrm{SMA}^{+} / \mathrm{mEGFP}^{+}$or $\mathrm{S} 100 \mathrm{~A} 4^{+} / \mathrm{mEGFP}^{+}$ double-positive cells appeared more in alveoli with obvious fibrosis and less in regions with mild fibrosis or even normal fibrosis. In future studies, the proportion of positive cells will be observed according to different stages of pulmonary fibrosis, which may be of great significance. Finally, the present results were all from animal experiments, which require to be confirmed in clinical patient samples if possible.

In conclusion, the present study identified descendants of epithelial cells in the fibrotic region. A small number of mEGFP-positive cells had co-localization of $\alpha$-SMA and S100A4, which indicated that EMT contributed to the pathogenesis of pulmonary fibrosis; however, it was not the major causative factor of pulmonary fibrosis.

\section{Acknowledgements}

Not applicable.

\section{Funding}

This work was supported by the National Natural Science Foundation of China (grant no. 31271231).

\section{Availability of data and materials}

The datasets used and/or analyzed during the current study are available from the corresponding author on reasonable request.

\section{Authors' contributions}

CC designed the experiments, completed and revised the writing of the manuscript. WT performed the main experimental work 
and was involved in drafting the manuscript. YW contributed to data acquisition and analysis. YC made contributions to the conception and design of the study, and manuscript revision. All authors read and approved the manuscript. YW and YC confirm the authenticity of all the raw data.

\section{Ethics approval and consent to participate}

All animal experiments were performed according to the Guidelines for Animal Care of CMU were and approved by the IACUC of CMU (IACUC issue no. 14031M). All applicable international, national and institutional guidelines for the care and use of animals were followed.

\section{Patient consent for publication}

Not applicable.

\section{Competing interests}

The authors declare that they have no competing interests.

\section{References}

1. Barratt SL, Creamer A, Hayton C and Chaudhuri N: Idiopathic pulmonary fibrosis (IPF): An overview. J Clin Med 7: 201, 2018.

2. Raghu G, Remy-Jardin M, Myers JL, Richeldi L, Ryerson CJ, Lederer DJ, Behr J, Cottin V, Danoff SK, Morell F, et al: Diagnosis of idiopathic pulmonary fibrosis. An official ATS/ERS/JRS/ALAT clinical practice guideline. Am J Respir Crit Care Med 198: e44-e68, 2018.

3. Richeldi L, Collard HR and Jones MG: Idiopathic pulmonary fibrosis. Lancet 389: 1941-1952, 2017.

4. Moeller A, Gilpin SE, Ask K, Cox G, Cook D, Gauldie J, Margetts PJ, Farkas L, Dobranowski J, Boylan C, et al: Circulating fibrocytes are an indicator of poor prognosis in idiopathic pulmonary fibrosis. Am J Respir Crit Care Med 179: 588-594, 2009.

5. Selman M and Pardo A: The leading role of epithelial cells in the pathogenesis of idiopathic pulmonary fibrosis. Cell Signal 66: $109482,2020$.

6. Nieto MA, Huang RY, Jackson RA and Thiery JP: EMT: 2016. Cell 166: 21-45, 2016.

7. Salton F, Ruaro B, Confalonieri $\mathrm{P}$ and Confalonieri M: Epithelial-mesenchymal transition: A major pathogenic driver in idiopathic pulmonary fibrosis? Medicina (Kaunas) 56: 608, 2020.

8. Salton F, Volpe MC and Confalonieri M: Epithelial-mesenchyma transition in the pathogenesis of idiopathic pulmonary fibrosis. Medicina (Kaunas) 55: 83, 2019.

9. Kim KK, Kugler MC, Wolters PJ, Robillard L, Galvez MG, Brumwell AN, Sheppard D and Chapman HA: Alveolar epithelial cell mesenchymal transition develops in vivo during pulmonary fibrosis and is regulated by the extracellular matrix. Proc Natl Acad Sci USA 103: 13180-13185, 2006.

10. DeMaio L, Buckley ST, Krishnaveni MS, Flodby P, Dubourd M, Banfalvi A, Xing Y, Ehrhardt C, Minoo P, Zhou B, et al: Ligand-independent transforming growth factor- $\beta$ type I receptor signalling mediates type I collagen-induced epithelial-mesenchymal transition. J Pathol 226: 633-644, 2012

11. Kim KK, Wei Y, Szekeres C, Kugler MC, Wolters PJ, Hill ML, Frank JA, Brumwell AN, Wheeler SE, Kreidberg JA and Chapman HA: Epithelial cell alpha3betal integrin links beta-catenin and Smad signaling to promote myofibroblast formation and pulmonary fibrosis. J Clin Invest 119: 213-224, 2009.

12. Tanjore H, Xu XC, Polosukhin VV, Degryse AL, Li B, Han W, Sherrill TP, Plieth D, Neilson EG, Blackwell TS and Lawson WE: Contribution of epithelial-derived fibroblasts to bleomycin-induced lung fibrosis. Am J Respir Crit Care Med 180 657-665, 2009.
13. Degryse AL, Tanjore H, Xu XC, Polosukhin VV, Jones BR, McMahon FB, Gleaves LA, Blackwell TS and Lawson WE: Repetitive intratracheal bleomycin models several features of idiopathic pulmonary fibrosis. Am J Physiol Lung Cell Mol Physiol 299: L442-L452, 2010.

14. Degryse AL, Tanjore $\mathrm{H}, \mathrm{Xu} \mathrm{XC}$, Polosukhin VV, Jones BR, Boomershine CS, Ortiz C, Sherrill TP, McMahon FB, Gleaves LA, et al: TGF $\beta$ signaling in lung epithelium regulates bleomycin-induced alveolar injury and fibroblast recruitment. Am J Physiol Lung Cell Mol Physiol 300: L887-L897, 2011.

15. Rock JR, Barkauskas CE, Cronce MJ, Xue Y, Harris JR, Liang J, Noble PW and Hogan BL: Multiple stromal populations contribute to pulmonary fibrosis without evidence for epithelial to mesenchymal transition. Proc Natl Acad Sci USA 108: E1475-E1483, 2011.

16. Chilosi M, Caliò A, Rossi A, Gilioli E, Pedica F, Montagna L, Pedron S, Confalonieri M, Doglioni C, Ziesche R, et al: Epithelial to mesenchymal transition-related proteins ZEB1, $\beta$-catenin, and $\beta$-tubulin-III in idiopathic pulmonary fibrosis. Mod Pathol 30: 26-38, 2017.

17. Harada T, Nabeshima K, Hamasaki M, Uesugi N, Watanabe K and Iwasaki H: Epithelial-mesenchymal transition in human lungs with usual interstitial pneumonia: Quantitative immunohistochemistry. Pathol Int 60: 14-21, 2010.

18. Livak KJ and Schmittgen TD: Analysis of relative gene expression data using real-time quantitative PCR and the 2(-Delta Delta $\mathrm{C}(\mathrm{T})$ ) method. Methods 25: 402-408, 2001.

19. Boye K and Maelandsmo GM: S100A4 and metastasis: A small actor playing many roles. Am J Pathol 176: 528-535, 2010.

20. B Moore B, Lawson WE, Oury TD, Sisson TH, Raghavendran K and Hogaboam CM: Animal models of fibrotic lung disease. Am J Respir Cell Mol Biol 49: 167-179, 2013.

21. Mouratis MA and Aidinis V: Modeling pulmonary fibrosis with bleomycin. Curr Opin Pulm Med 17: 355-361, 2011.

22. Moore BB and Hogaboam CM: Murine models of pulmonary fibrosis. Am J Physiol Lung Cell Mol Physiol 294: L152-L160, 2008.

23. Degryse AL and Lawson WE: Progress toward improving animal models for idiopathic pulmonary fibrosis. Am J Med Sci 341: 444-449, 2011

24. Lawson WE, Polosukhin VV, Stathopoulos GT, Zoia O, Han W, Lane KB, Li B, Donnelly EF, Holburn GE, Lewis KG, et al: Increased and prolonged pulmonary fibrosis in surfactant protein C-deficient mice following intratracheal bleomycin. Am J Pathol 167: 1267-1277, 2005.

25. Adamson IY and Bowden DH: The pathogenesis of bloemycin-induced pulmonary fibrosis in mice. Am J Pathol 77: 185-197, 1974.

26. Yoldas O, Karaca T, Bilgin BC, Yilmaz OH, Simsek GG, Alici IO, Uzdogan A, Karaca N, Akin T, Yoldas S and Akbiyik F: Tamoxifen citrate: A glimmer of hope for silicosis. J Surg Res 193: 429-434, 2015.

27. El Agha E, Moiseenko A, Kheirollahi V, De Langhe S, Crnkovic S, Kwapiszewska G, Szibor M, Kosanovic D, Schwind F, Schermuly RT, et al: Two-way conversion between lipogenic and myogenic fibroblastic phenotypes marks the progression and resolution of lung fibrosis. Cell Stem Cell 20: 261-273.e3, 2017.

28. Perl AK, Wert SE, Nagy A, Lobe CG and Whitsett JA: Early restriction of peripheral and proximal cell lineages during formation of the lung. Proc Natl Acad Sci USA 99: 10482-10487, 2002

29. Schafer MJ, White TA, Iijima K, Haak AJ, Ligresti G, Atkinson EJ, Oberg AL, Birch J, Salmonowicz H, Zhu Y, et al: Cellular senescence mediates fibrotic pulmonary disease. Nat Commun 8: 14532, 2017.

30. Chen X, Xu H, Hou J, Wang H, Zheng Y, Li H, Cai H, Han X and Dai J: Epithelial cell senescence induces pulmonary fibrosis through Nanog-mediated fibroblast activation. Aging (Albany NY) 12: 242-259, 2019.

31. Pirici D, Mogoanta L, Kumar-Singh S, Pirici I, Margaritescu C, Simionescu C and Stanescu R: Antibody elution method for multiple immunohistochemistry on primary antibodies raised in the same species and of the same subtype. J Histochem Cytochem 57: 567-575, 2009.

32. Bolognesi MM, Manzoni M, Scalia CR, Zannella S, Bosisio FM, Faretta $\mathrm{M}$ and Cattoretti G: Multiplex staining by sequential immunostaining and antibody removal on routine tissue sections. J Histochem Cytochem 65: 431-444, 2017.

33. Borensztajn K, Crestani B and Kolb M: Idiopathic pulmonary fibrosis: From epithelial injury to biomarkers-insights from the bench side. Respiration 86: 441-452, 2013. 
34. Bagnato $\mathrm{G}$ and Harari S: Cellular interactions in the pathogenesis of interstitial lung diseases. Eur Respir Rev 24: 102-114, 2015.

35. Yamaguchi M, Hirai S, Tanaka Y, Sumi T, Miyajima M, Mishina T, Yamada G, Otsuka M, Hasegawa T, Kojima T, et al: Fibroblastic foci, covered with alveolar epithelia exhibiting epithelial-mesenchymal transition, destroy alveolar septa by disrupting blood flow in idiopathic pulmonary fibrosis. Lab Invest 97: 232-242, 2017

36. Xia H, Gilbertsen A, Herrera J, Racila E, Smith K, Peterson M, Griffin T, Benyumov A, Yang L, Bitterman PB and Henke CA: Calcium-binding protein S100A4 confers mesenchymal progenitor cell fibrogenicity in idiopathic pulmonary fibrosis. J Clin Invest 127: 2586-2597, 2017.
37. Lee JU, Chang HS, Shim EY, Park JS, Koh ES, Shin HK, Park JS and Park CS: The S100 calcium-binding protein A4 level is elevated in the lungs of patients with idiopathic pulmonary fibrosis. Respir Med 171: 105945, 2020.

This work is licensed under a Creative Commons Attribution-NonCommercial-NoDerivatives 4.0 International (CC BY-NC-ND 4.0) License. 